\title{
A Smart Cloud-based System for the WEEE Recovery/Recycling
}

\author{
Xi Vincent Wang \\ Department of Production Engineering, KTH Royal Institute of Technology, Sweden \\ Brinellvägen 68, 11428 Stockholm, Sweden \\ wangxi@kth.se
}

Brenda N. Lopez N

State Key Joint Laboratory of Environment Simulation and Pollution Control (SKLESPC), Room 813, School of the Environment, Tsinghua University,

Haidian District, Beijing, China, 100084

loujl10@mails.tsinghua.edu.cn

\section{Winifred ljomah}

Design, Manufacture and Engineering Management, Faculty of Engineering, (DMEM)

University of Strathclyde, UK

131 Rotten Row, Glasgow G4 0NG, United Kingdom

w.I.ijomah@strath.ac.uk

\section{Lihui Wang}

Department of Production Engineering, KTH Royal Institute of Technology, Sweden Brinellvägen 68, 11428 Stockholm, Sweden

lihuiw@kth.se

\section{Jinhui Li}

State Key Joint Laboratory of Environment Simulation and Pollution Control (SKLESPC), Room 804, School of the Environment, Tsinghua University

Haidian District, Beijing, China, 100084

jinhui@tsinghua.edu.cn 


\begin{abstract}
Waste Electrical and Electronic Equipment (WEEE) is both valuable and harmful since it contains a large number of profitable and hazardous materials and elements at the same time. At component level, many parts of the discarded equipment are still functional and recoverable. Thus it is necessary to develop a distributed and intelligent system to support WEEE component recovery and recycling. In recent years, the Cloud concept has gained increasing popularity since it provides a service-oriented architecture that integrates various resources over the network. Cloud Manufacturing systems are proposed world-wide to support operational manufacturing processes. In this research, Cloud Manufacturing is further extended to the WEEE recovery and recycling context. A Cloud-based WEEE Recovery system is developed to provide modularized recovery services on the Cloud. A data management system is developed as well, which maintains the knowledge throughout the product lifecycle. A product tracking mechanism is also proposed with the help of the Quick Respond code method.
\end{abstract}

\title{
INTRODUCTION
}

The amount of Waste Electrical and Electronic Equipment (WEEE) has grown significantly in recent years, due to increased Electrical and Electronic Equipment (EEE) and its shorter lifecycle. Different types of EEE are principally classified as shown in Table 1. The replacements of these devices (e.g. televisions, computers, cell phones, etc.) are more frequent than ever before because of the fast-changing market demand and planned obsolescence. New products offer attractive functionalities and convenience to the consumer, but also push the in-service products from Middle-Of-Life (MOL) to EndOf-Life (EOL) phase. From the Manufacturers' perspectives, shorter lifecycle brings greater profits and keeps their positions on the competitive market. However, it also 
creates huge volume of WEEE that leads to global environment issues on many scales. According to the statistics of the US Environmental Protection Agency [1], 438 million new electronic devices were sold in 2009 in America, which represented a doubling of sales from 1997. 2.37 million tons of them reached EOL in 2009 , but only $25 \%$ of them were collected for recycling. Among different kinds of electrical and electronic products, the recycling rate of mobile devices (cell phones, smart phones, PDAs) was lowest, even less than $9 \%$.

Table 1. Principal EEE Categories

\begin{tabular}{ll} 
Category & Examples \\
\hline Information and Communication & Computer, tablet, mobile phone \\
Large household appliances & $\begin{array}{l}\text { Refrigerator, air conditioner, washing } \\
\text { machine }\end{array}$ \\
Small household appliances & Iron, dryer, rice cooker \\
Lighting equipment & Electric light bulb, household luminary \\
Electrical and electronic tools & Volt-Ohm-Millimetre, soldering iron \\
Toys, leisure and sports equipment & Coin slot machines, car racing set \\
Automatic dispensers & Water dispenser, coffee machine \\
Medical equipment & Ultrasound machine, heart-lung machine \\
\hline
\end{tabular}

Thus it is important to manage and control WEEE with practical strategies. In the EU, handling WEEE is a high priority for all member states. Countries such as Switzerland, Denmark, Netherlands, Norway, Belgium, Sweden, and Germany already have an established Extended Producer Responsibility (EPR) for WEEE. In the case of WEEE facilities, many developed countries including the USA, Europe and Japan have mature technologies for the treatment of this waste stream [2]. However, in developing countries primitive activities predominate, as in the case of the largest e-waste recycling place in Guiyu, China where the practices include: manually classification and 
dismantling of e-waste, manual separation and solder recovery for mounted printed circuit board, precious metal extraction by acid, among others [3]. Also the informal sector has a predominant presence in these activities, as in the case of Nigeria, Ghana and Thailand [2]. Traditionally, the recycling of WEEE mainly stays at material level. The target of recycling is either separating hazardous elements from resources, e.g. mercury and brominated flame retardant or extracting valuable materials that can be utilized again, e.g. gold, silver, plastics, steel and aluminium. The risk in WEEE treatment is largely due to its toxicity. During WEEE recycling, three groups of substances may be released: the constituents of the EEE, the substances used in the recycling techniques, and the by-products formed during transformation of the original constituents $[4,5]$. The toxicity of these substances is related to the presence of heavy metals and halogenated flame retardants. When treated by poorly controlled processes, it leads to damage and risk in multiple scales: soil and sediment pollution [6, 7], water [8], air [9], and human health $[10,11]$. Additionally, the pollution may also infiltrate into the environment directly through municipal solid waste disposal [12].

The traditional path of WEEE is limited to recycling, for the sake of obtaining raw materials. In practice, it is possible to treat WEEE as used products, before it is considered as a discharged waste [13]. The EOL processes include the secondary market processing and component recovery (repair, reconditioning, and remanufacturing) or material recovery (recycling) [14]. According to the EU WEEE directive, after electronics reach the end phase of their lifecycle, they should be filtered based on their status based on their economic and functional potentials. Then the WEEE is processed via different 
paths after proper treatment, but principally WEEE is recycled. In practice, it is also important to consider other EOL processing routes, for example the BS 8887 standard serials give six EOL routes as follows, along with the likely change at warranty level compared with the original product [15], including reuse, remanufacture, recondition, repurpose, recycle, and dispose. In this roadmap, WEEE are handled not only as a waste, but also as a special category of product that can be re-used through an extended lifecycle [13]. Although the term WEEE indicates the equipment as a waste, a huge proportion of the equipment can be defined as Used Electrical and Electronic Equipment (UEEE), which plays an important role for component recovery or extended usage. These activities are at a higher level than recycling in the environmental hierarchy of EOL strategies [14]. Considering this, such understanding can be included in the new perception of the EEE lifecycle. It is possible to put UEEE back to the market via proper recovery processes and treatments (Figure 1.).

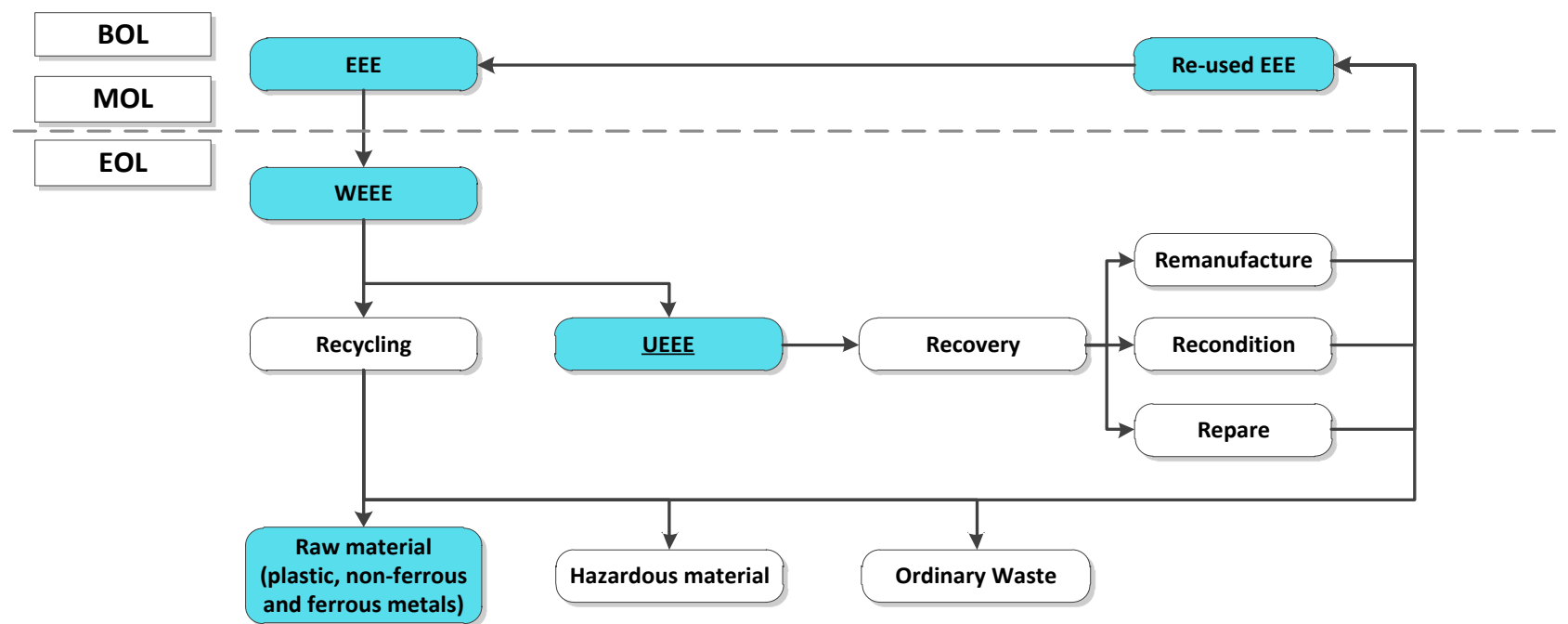

Figure 1. WEEE Physical Flow and UEEE

Recovery activities aim to get usage of the components from UEEE, before they are disposed as waste, i.e. repair, reconditioning and remanufacturing. The assessment 
and utilization can be extended to the functionality level [14]. After being disassembled, the parts from UEEE can be re-utilized for different purposes based on their warranty conditions. Even though the product as a whole has reached its end of lifecycle, many parts inside it may still be functional [16]. One of the most successful business examples of profitable component recovery is the remanufacturing of parts in the automotive industry, and large mechanical and electromechanical products. Since the waste vehicles are able to provide profitable parts for repairing other vehicles still in service, these parts are not treated as waste any longer. They can be tagged as used products and be offered back to the market with reasonable warranties. It is similar in UEEE scenarios. Instead of treatment for valuable or dangerous materials, many parts within UEEE can be re-utilized at functionality level. It is necessary to establish a platform that understands both the nature of WEEE/UEEE and integrates related processes. Then a collaborative environment can be established to maintain the data/knowledge and support component recovery and recycling processes. In this paper, a Cloud-based system is developed to support the WEEE recycling and component recovery processes, including remanufacturing, reconditioning and repairing. The architecture of the proposed system, namely WEEE Component Recovery/Recycling Cloud (WR2Cloud), and its development are introduced in the following sections.

In this paper, a cloud based system is developed to support not only the management of WEEE, considered as a waste, by recycling, but also the fraction of WEEE that is an UEEE by recovery and related processes, including remanufacturing, reconditioning and repairing. The architecture of the proposed system, namely WEEE 
Recovery/Recycling Cloud (WR2Cloud), and developments are introduced in the following sections.

\section{SYSTEM FRAMEWORK}

As mentioned above, an intelligent recovery and recycling system is required to support the management of WEEE at both material and functionality level. In recent years, Cloud technology has been introduced in different scenarios since it provides the capability of scalable and flexible services in a customized manner. The Cloud concept was initially proposed to describe the large number of computers that are connected via runtime communications over a network [17]. Then the Cloud was extended to other areas supporting flexible and customized services, e.g. manufacturing. Cloud manufacturing can be understood as the manufacturing model that enables scalable, ondemand access to manufacturing services, both digitally and physically [18]. As a specific category of manufacturing, the re-production based on WEEE, especially UEEE can be also supported by Cloud via its integrated manufacturing solutions, high-level data management/control and flexible service models. Thus, a Cloud-based system is developed to fulfil the needs of WEEE.

\section{SYSTEM REQUIREMENTS AND ROLES}

In the manufacturing paradigm, raw material is treated as the input for the start

of a physical flow. The order, payment and transportation of raw materials can proceed within a mature supplier network. This is one of the major differences between traditional manufacturing and the WEEE component recovery/recycling business. In 
WEEE component recovery/recycling, used products are owned by random end users. These users' locations are usually unknown and their behaviour, e.g. in terms of where and when they would discard their used products are unpredictable. It is specifically difficult to maintain the knowledge of WEEE and organize related services due to the interrupted information flow.

With the help of Cloud, all the data of individual WEEE can be maintained in an integrated and shared information pool. The centralized Cloud repository also keeps the Beginning-Of-Life (BOL) and Middle-Of-Life (MOL) specifications of products. In this way, remote customers, who are connected to the Cloud via the network, can access and so update the status at all stages of lifecycle. The system would also assist service scheduling after the product reaches EOL. The system requirement for data management can be summarized as illustrated (Figure 2).

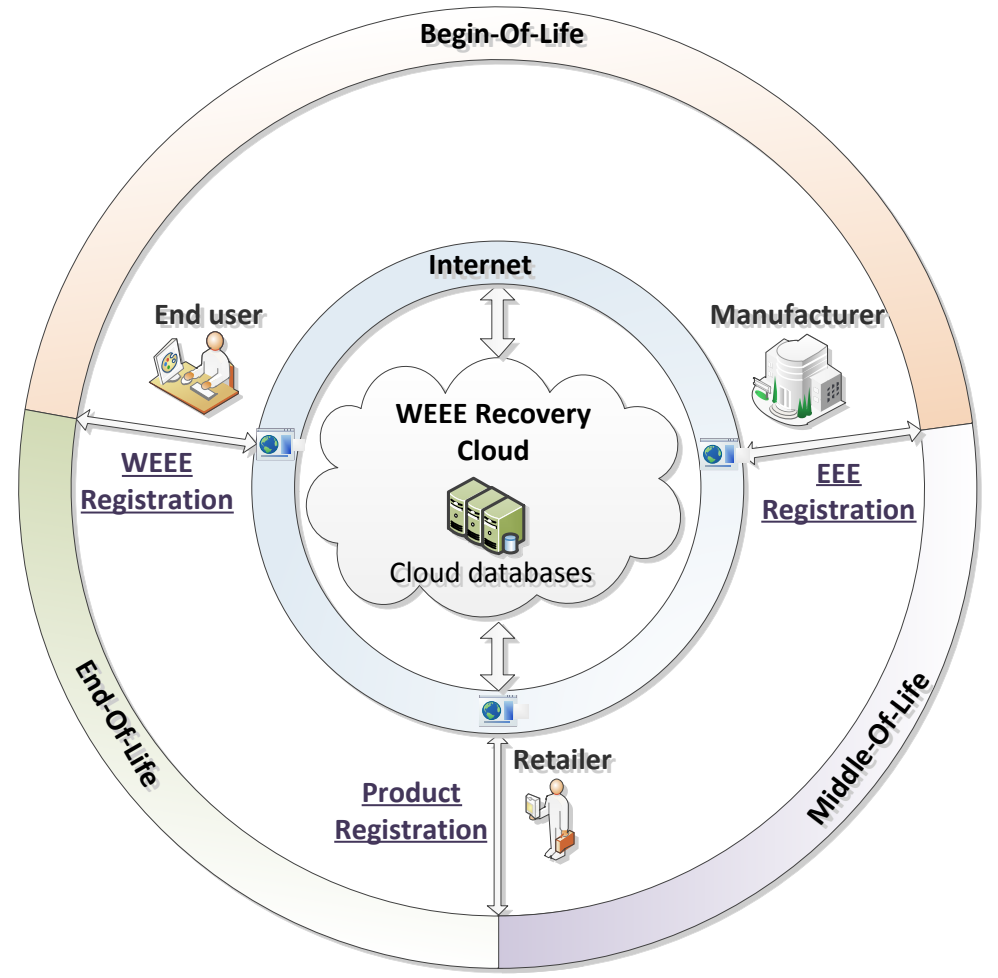

Figure 2. Cloud-based WEEE Data Maintenance 
Such information management needs support from manufacturers, retailers and end users. A key differentiating factor of this new system from typical production activities is that the WR2Cloud is able to integrate product knowledge and data throughout the lifecycle of products. An integrated and unified data sharing/management mechanism is an important prerequisite for recovery and recycling services. With the help of Cloud databases, Cloud participants are able to retrieve and stream WEEE data dynamically. The business model for this Cloud system is shown in Figure 3.

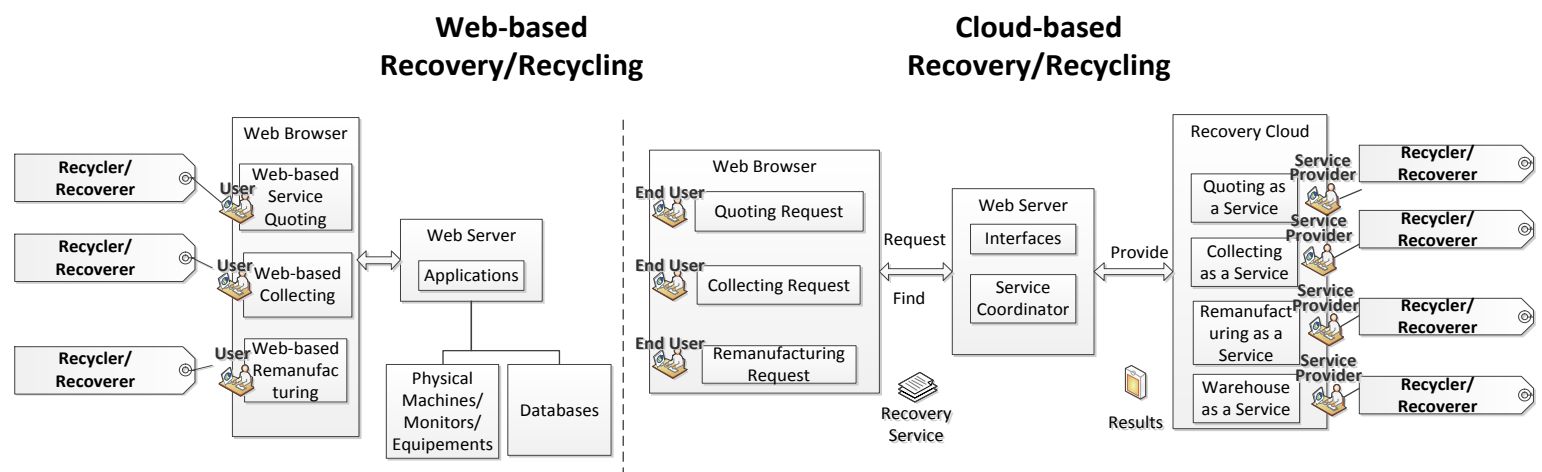

Figure 3. WR2Cloud Business Model

Even though the Cloud-based solutions are implemented based on some webbased technologies, it needs to be pointed out that there are fundamental differences between traditional WEEE systems and the recovery/recycling Cloud. Firstly, from the stakeholder's perspective, in traditional web-based recovery and recycling systems [19, 20] the users of the system or platform are mainly recyclers or remanufacturers. The system helps them to communicate with remote resources over the network. In WR2Cloud system, the users of the system are the end users or consumers of the EEE. 
Participants that are related to recovery and recycling processes act as the service providers in the Cloud, e.g. collecting and recycling service providers. The role of the recyclers and remanufacturers changes from end users to providers.

Additionally, the capability delivery of the Cloud recovery/recycling system is also different from conventional solutions. In the Cloud, recovery resources and capabilities are packaged as service modules and published, for example quoting-as-a-service and warehouse-as-a-service. In this way, the users do not directly interact with the recovery and recycle activities. Instead they are supported by the everything-as-a-service (XaaS) model that is deployed by the service providers in the Cloud.

From the perspective of a business model, the traditional web-based system supports the customer with the whole infrastructure, which forms a One-to-One business model. In the Cloud, multiple service objectives are achieved by the whole Cloud. The customers may or may not need to know the identifications of the providers or their whereabouts or vice versa. It forms a Many-to-Many model. Service requests and results are transferred by the coordinator mechanism between users and Cloud. Thus it forms a "request-find-provide" procedure for the recycling/recovery business.

\section{WR2CLOUD: SYSTEM FRAMEWORK}

To meet the requirements mentioned above, a three layer system is developed to support WEEE recovery/recycling activities (Figure 4). In the WR2Cloud component recovery and recycling facilities and capabilities are provided as Cloud service packages in the Cloud layer. The outlines and specifications of these services are maintained in the Cloud database and published at the Cloud service coordinator layer. The service 
coordinator acts as the neutral supervisor or orchestrator of the Cloud system. Based on these detailed descriptions, the service coordinator is able to search for appropriate service solutions, to organize optimized service combinations, and to execute service tasks. As a Service-Oriented Architecture (SOA), the WR2Cloud is able to coordinate the input/output flow through service packages and offer them as a concrete virtual service combination. At the user layer, the end-users are able to access the system from their local web browsers over the network. Different interfaces are developed to support their needs in recovery and recycling, e.g. registration, updating, service querying, resource tracking, etc.

\section{DEVELOPMENT: CLOUD, STANDARDS AND PRODUCT TRACKING MECHANISM}

Comparison of different treatments of WEEE is important for evaluating related environmental impacts. The factors to be considered include benefits and risks from the different stages in the WEEE management, the emission rate (quantity of WEEE produced or expected to be produced), the reverse logistic chain, the toxicity (hazardous materials content), and the extent of the environmental impact among different treatments. 


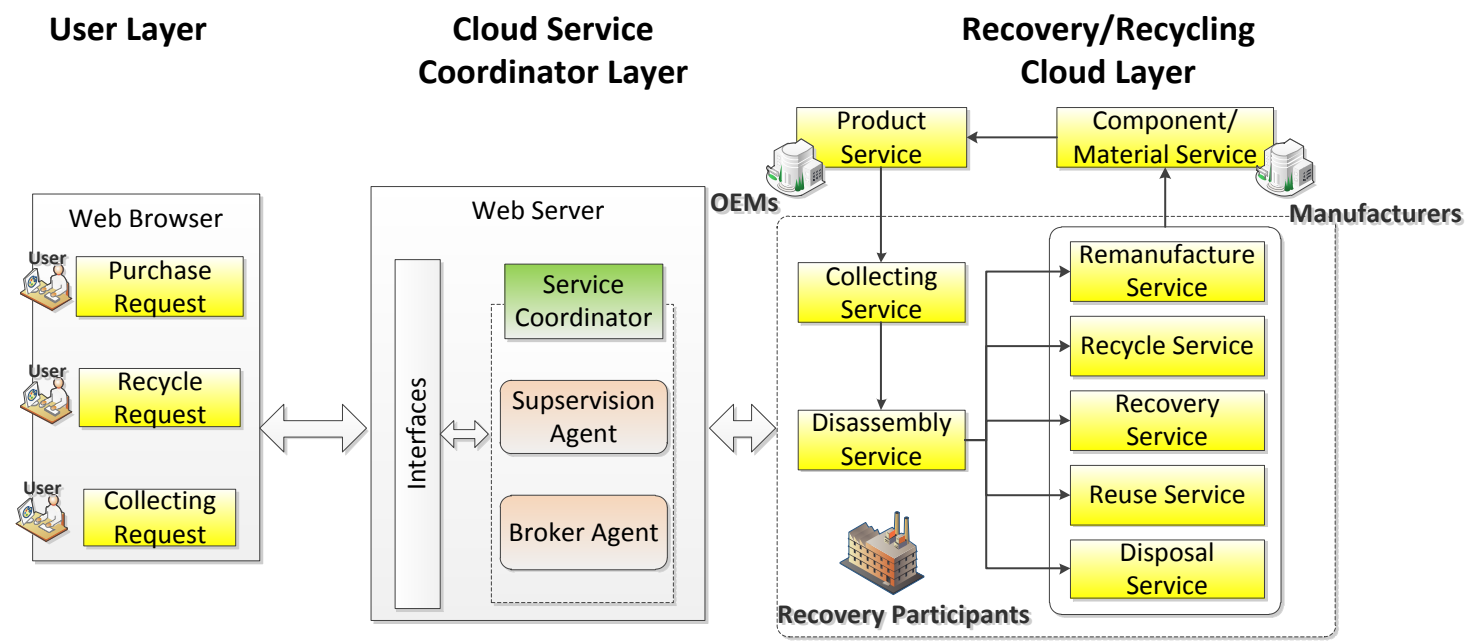

Figure 4. Three-layer WR2Cloud

The materials present in the EEE or future WEEE still play an important role [14].

A wide variety and large quantities of products exists in the EEE context (Table 1), and their internal composition is also complex. First it is important to understand that the materials content depends on the kind of equipment under consideration. For example, for large domestic appliances there is a considerable quantity of metals. However, in the case of small appliances, there are individual components such as cartridges, batteries, cables, printed circuit boards, ferrous and nonferrous fractions thus a wider range of materials is present and typically in smaller quantities. With the help of the Cloud-based environment, it is possible to document different types of EEE products and maintain the knowledge database of their compositions.

Environmental impacts of WEEE need to be evaluated before decision making. It has to be admitted that both positive and negative impact factors exist during the recovery and recycle processes. For example, component recovery (also called remarket processes) adds new value to the WEEE (especially UEEE), to bring the used products back to working order and this can be considered a positive factor. However, these 
recovery activities could also bring negative impacts to the environment occasionally, for example due to the chemicals and energy used in the product recovery process. In the recycling (material recovery) cases, when the products are reversed back to their raw materials, the energy and resources used for its original manufacture are lost. Moreover, energy and resource is required to enable this return to raw material thus energy and resource are lost twice over; and even more energy and resource would be needed to turn the raw material into a useable object. Thus it is important to assess the environmental impacts of different strategies of component recovery or material recycling before they are processed [14]. It is well known that inappropriate recycling procedures output high environmental impact, such as the air pollution from burning and dismantling activities, ashes from incineration, fly ashes and bottom ashes with high concentration of dioxins, $\mathrm{Pb}$ (industrial soils), PBDEs (urban soils), and also leaching potential [4].

Yet the systematic recycling process offers important environmental benefits in saving natural resources. Another issue to consider is the transportation of WEEE, which leads to high cost and negative environment impacts as well because of the energy and resources consumption during transportation. One solution could be locating processing plants in close proximity, for example recyclers and remanufacturers. Thus products that are not suitable for remanufacture could be put through recycling (and vice versa) without much resource spent on transportation. Finally the highest negative environmental impact is the landfill of WEEE without processing, which implies disposal of toxic materials without treatment. Therefore, the Cloud-based approach is expected 
to be able to evaluate and optimize the WEEE recovery and recycling process at a high level and also deliver sustainable service strategies.

\section{WR2CLOUD Standards: APIs for Service Packages, Service Providers and Service Consumers}

In the WR2Cloud, the information management and data sharing is supported by a standardized environment. Data models are developed to describe the important elements throughout the recovery and recycling chain, e.g. end-user, service provider, service model, etc. Uniformed Application Protocol Interfaces (APIs) are utilized to connect these models and provide an interoperable solution for the processes and interactions in the Cloud (Figure 5). In this SOA, the data description methodology is also built based on the service-oriented principle. The core of the data model set is the Cloud Service data model that documents what kind of recovery or recycling service is requested and how it is archived. The EEE data model set is established based on current ISO 10303 standard serial [21, 22] and extensive developments on Cloud Manufacturing [23]. The top entity of Cloud recovery and recycling service is defined as "project". For one service case or task, it is maintained as a project that is supported by related recovery and recycling resources and service providers.

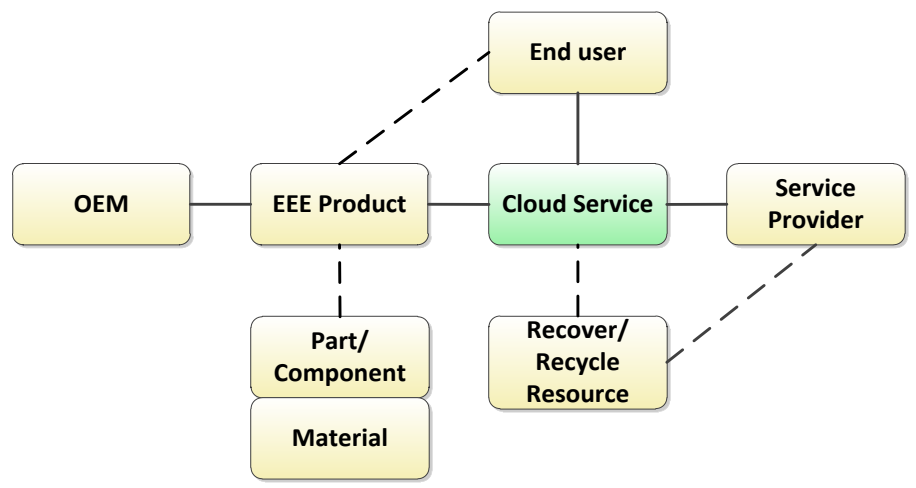

Figure 5. GREENet Data Model Set 
For WEEE, its knowledge maintenance starts from EEE product registration at the BOL phase. The Original Equipment Manufacturer is responsible for establishing and maintaining the details and specifications as discussed above. The components/subcomponents information is integrated with the product data model. In WR2Cloud, the data is documented at both component and material levels of the product. This information is especially valuable for the recovery and recycling processes afterwards. For instance, special element treatments are organized by the service coordinator based on the hazard element list of the WEEE product model, and the disassembly service can be assigned specifically for the valuable components.

After the EEE reaches the MOL stage, the end-users play the important role in updating the status of EEE or registering WEEE after its service ends. In practice, the WR2Cloud not only takes care of the WEEE process at the EOL phase, it also supports the EEE maintenance throughout the lifecycle of the product. The maintenance can be categorized in three groups, i.e. reactive maintenance, preventive maintenance and predictive maintenance [24].

- Reactive maintenance, or breakdown maintenance, can be described as a firefighting approach which allows the equipment/products to work till failure. With the integrated information sharing environment, the users are able to easily report faults or breakdowns via the Cloud platform. Customized maintenance solutions can be quickly organized based on the existing product specifications in the Cloud database, e.g. warranty status, model, customer location, etc. 
- Preventive maintenance is often referred to as use-based maintenance. It is comprised of maintenance activities that are undertaken after a period of time or amount of use. In the Cloud-based system, the Service provider is also able to interact with customers actively, e.g. reminding them of key component expiration and offering safety check/maintenance based on the usage/duration data in the Cloud.

- Predictive maintenance is frequently referred to as condition-based maintenance. For costly or important EEE products, the maintenance can be initialized with additional monitoring/diagnostic data, e.g. noise, temperature, corrosion, and so forth. Predictive maintenance reduces the possibility of the breakdowns on critical devices and parts

\section{“Cloud + QR"-based Tracking Methodology}

To further improve the performance and portability of WR2Cloud, the data integration mechanism can be supported by the Quick Response Code (QR Code). QR code is a type of matrix barcode or two-dimensional barcode that is an optically machine-readable label [25]. The labels can be attached to products or even components inside. The capacity of QR code has been improved greatly in recent years. The latest version is able to obtain up to 1852 characters with high error correction. In this research, an LCD television is chosen as the WEEE that is owned by an end-user. The basic information of the product is recorded in its QR code tag that is attached on the back of the product (Figure 6). In this case, 764 characters are utilized to document the 
information of the device, e.g. the product type, model, OEM and most importantly the unique product reference number. The user is able to scan the code via smart phones, tablets or camera devices and then submit queries to the Cloud via web browsers or mobile applications. Based on the serial number, the detailed product specifications can be quickly retrieved from the Cloud database. The user then links the latest WEEE status to the product profiles and registers it as WEEE. Related recovery and recycling services can be organized according to the information at both material level and component level. Compared with traditional barcode methods, more pollution and recovery data can be stored in the QR code tag, and additionally, for example, specifications compliant with the Restriction of the Hazardous Substances Directive. In this LCD case the pollutants and recyclable parts are recorded in the QR code which is visible to the end user. In this way, the user is able to understand the environmental, and recovery information in detail and request for the preferred services accordingly.

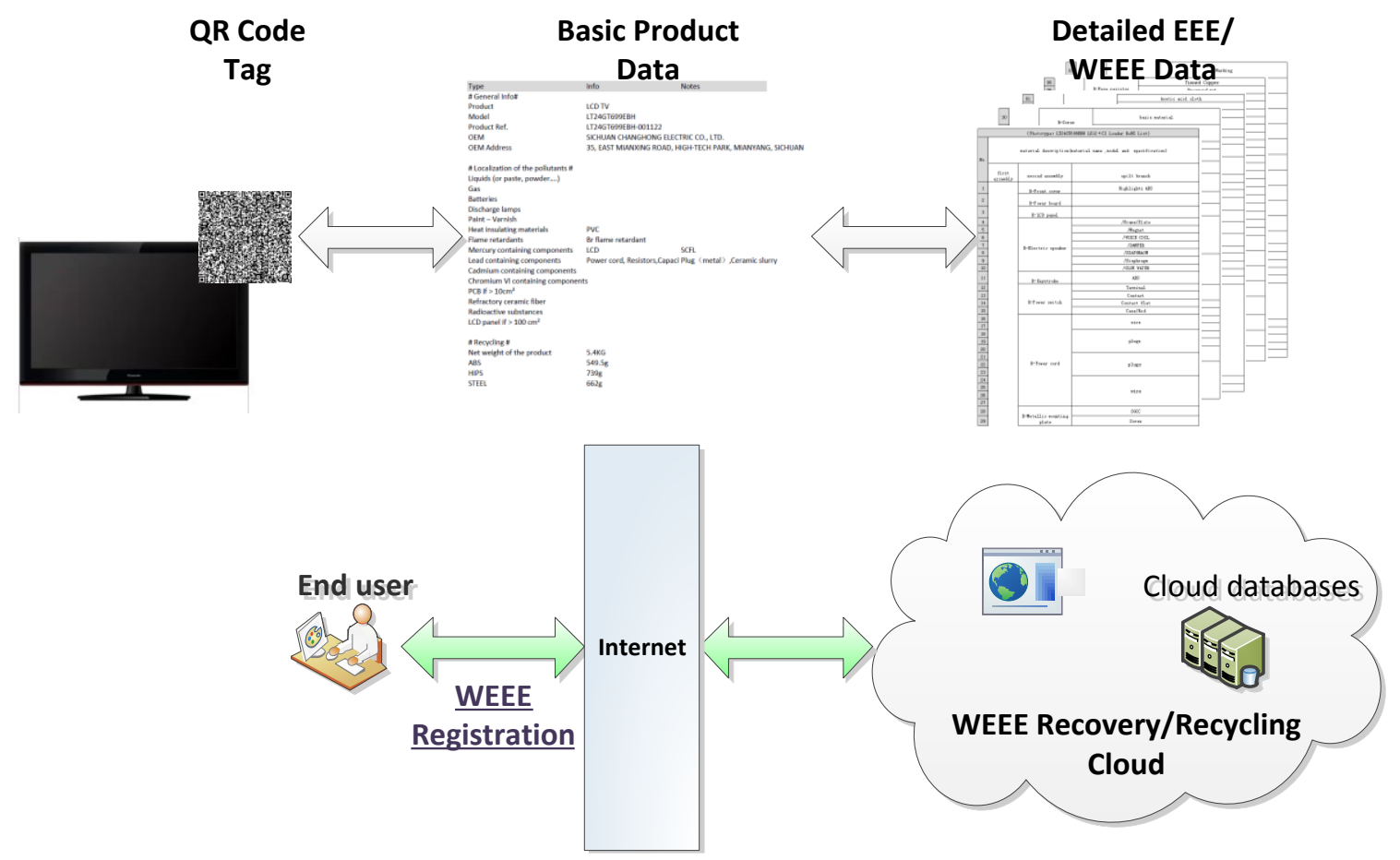




\section{Figure 6. QR Code Enabled Cloud Service}

\section{IMPLEMENTATIONS AND CASE STUDIES}

To evaluate the methods mentioned above, a Cloud-based remanufacturing system is implemented. At the preliminary phase, the virtual environment is built in the Cloud environment which contains 32 computing cores and more than $132 \mathrm{~GB}$ memories in total. With the help of extendable Cloud resources, the customers are able to access and maintain the WEEE Cloud without installing or configuring any local applications. The working environment of Cloud is capable of virtualizing multiple operation environments, i.e. Linux, MS Windows, and UNIX family. Thanks to the platform independency of JAVA, the developments can be deployed across different environments to suite the different needs or requirements of the users.

\section{Case Study 1: Cloud WEEE Management at Product level}

In the QR code management module, the remanufacturing stakeholders are able to generate the code tag and attach it on the product (Figure 7). When the product stops functioning, the customer is able to scan the tag and quickly upload it onto the Cloud. The basic information of the WEEE stored in the QR tag is directly interpreted by the system, and further details can be tracked based on the unique product ID kept in the tag. 


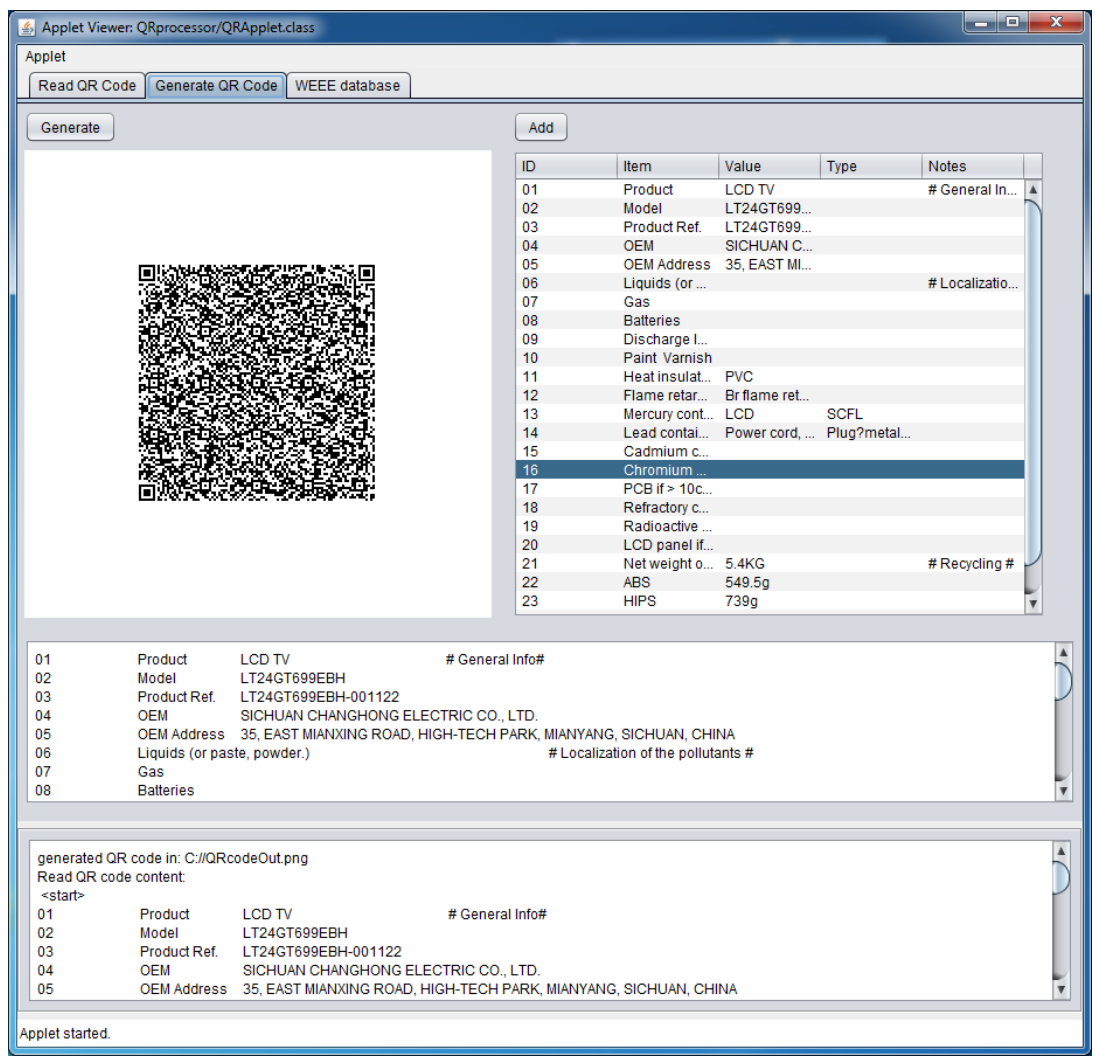

Figure 7. QR Code Processors

In the WEEE management module, MySQL databases are also established in the

Cloud. To better access and maintain the dynamic data of WEEE, a meta-model is developed in a flat structure. The object-oriented WR2Cloud standard is interpreted into the meta-model. Thus the Cloud user is able to understand and maintain the database without the expertise of the standards and schemas. Besides standardized product data, the Cloud database also maintains supporting documents e.g. instructions, designs, disassembly directives, etc.

In the graphical user interface, the user is able to view all the running databases and quickly locate more details of the product specifications based on the unique product ID (Figure 8). In the study case, the user is able to select from multiple databases, and also maintain the WEEE profile dynamically, including adding, deleting, 
and updating. In this case, the replacement of the LCD screen is added to the product specifications. When the product needs to be recovered in the future, all the changing and repairing records are integrated and extracted without further efforts.

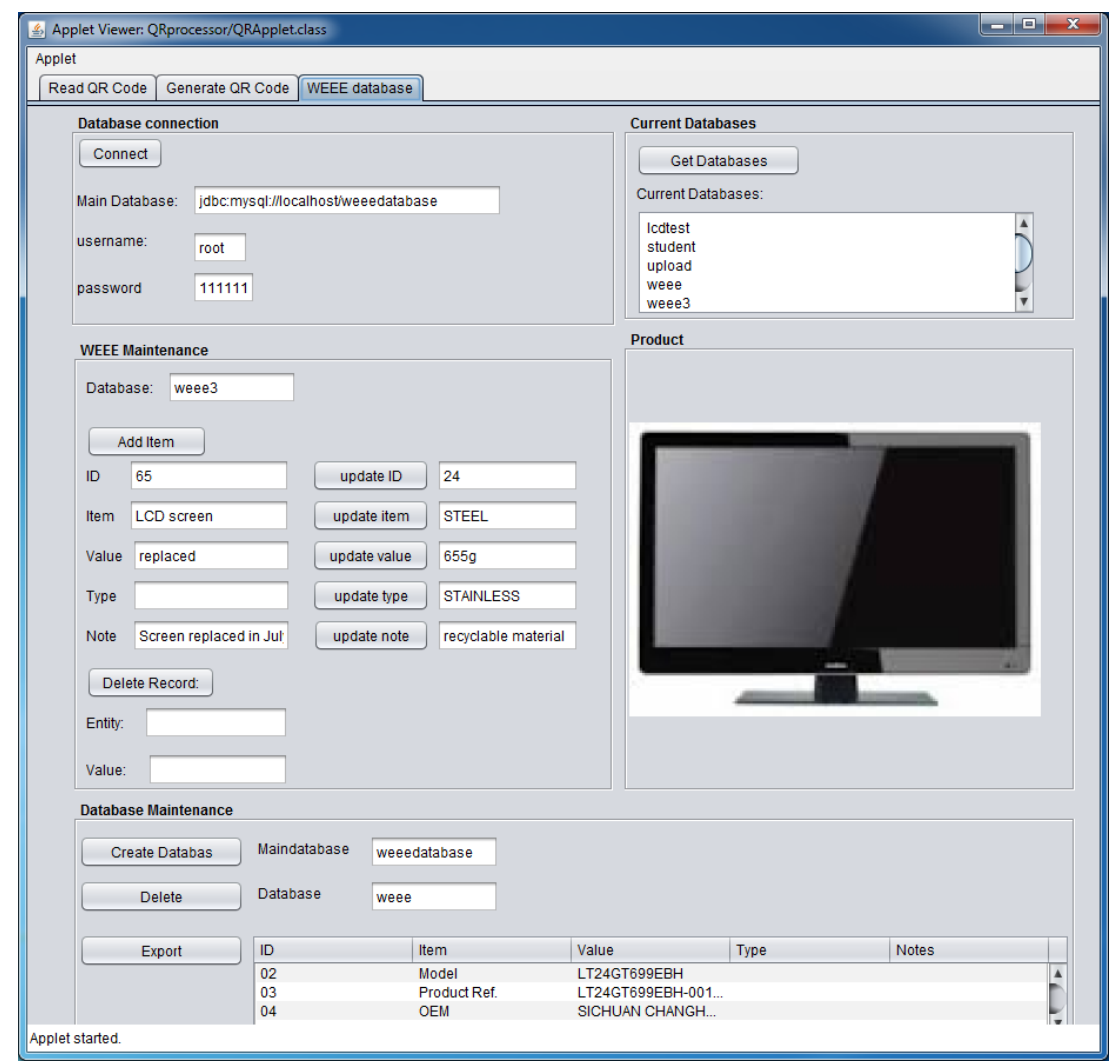

Figure 8. WEEE Management Module

Case Study 2: Cloud-based WEEE Management at National/International Level

After the WEEE information is maintained and integrated on the WR2Cloud, this method can be applied at the global level. Take another type of product, Used Lead Acid Batteries (ULAB), as an example: the ULAB case can represent how the information is organized. With the help of WR2Cloud, the decision makers are able to be informed of an item's whereabouts as raw material or product. 
In this case study, lead metal and LAB is monitored and managed by the proposed WR2Cloud from a global perspective. The material flow could be explained as follows: currently more than $80 \%$ [26] of lead metal productions are used in Lead Acid Batteries (LAB) and their recycling re-produces lead that could be used in future production of LAB, which is called secondary lead production. Another source of lead is from the primary production, which is produced by mining, especially as by-product of $\mathrm{Pb}-\mathrm{Zn}$ mines. The sum of the primary and secondary production is the total lead metal, which can be utilized by industry for lead acid batteries production. In this way, these two products are interconnected. Furthermore, the secondary production started to act as an important source for lead metal ingot also, due to its high recyclability [27]. Therefore, it is logical to investigate the management of the information about the movements of these two products in order to get the location information of the suppliers and consumers. The major consumers and suppliers in the world are China, the USA, the UK, Germany, Canada, Japan and India. These countries represent more than $75 \%$ of the global lead metal production in 2011. WR2Cloud, in this case, functions as a data and material bank, in order to understand the usage of lead metal. The material flow of lead metal includes production, consumption and export/import, which could be represented by the Physical Trade Balance (PTB). With the help of WR2Cloud, the PTB indicates if a country is a consumer or supplier in principle[28]. Thus, the total consumption of lead in a country is the result from its production plus its PTB. At the international level there are two data sessions maintained in the Cloud domain (Figure 9): one corresponds to import/export refined lead as raw material, while the other refers 
to $L A B$ as a product. The distribution of them during year 2011 is illustrated. In this case WR2Cloud is to monitor and documents these trades.

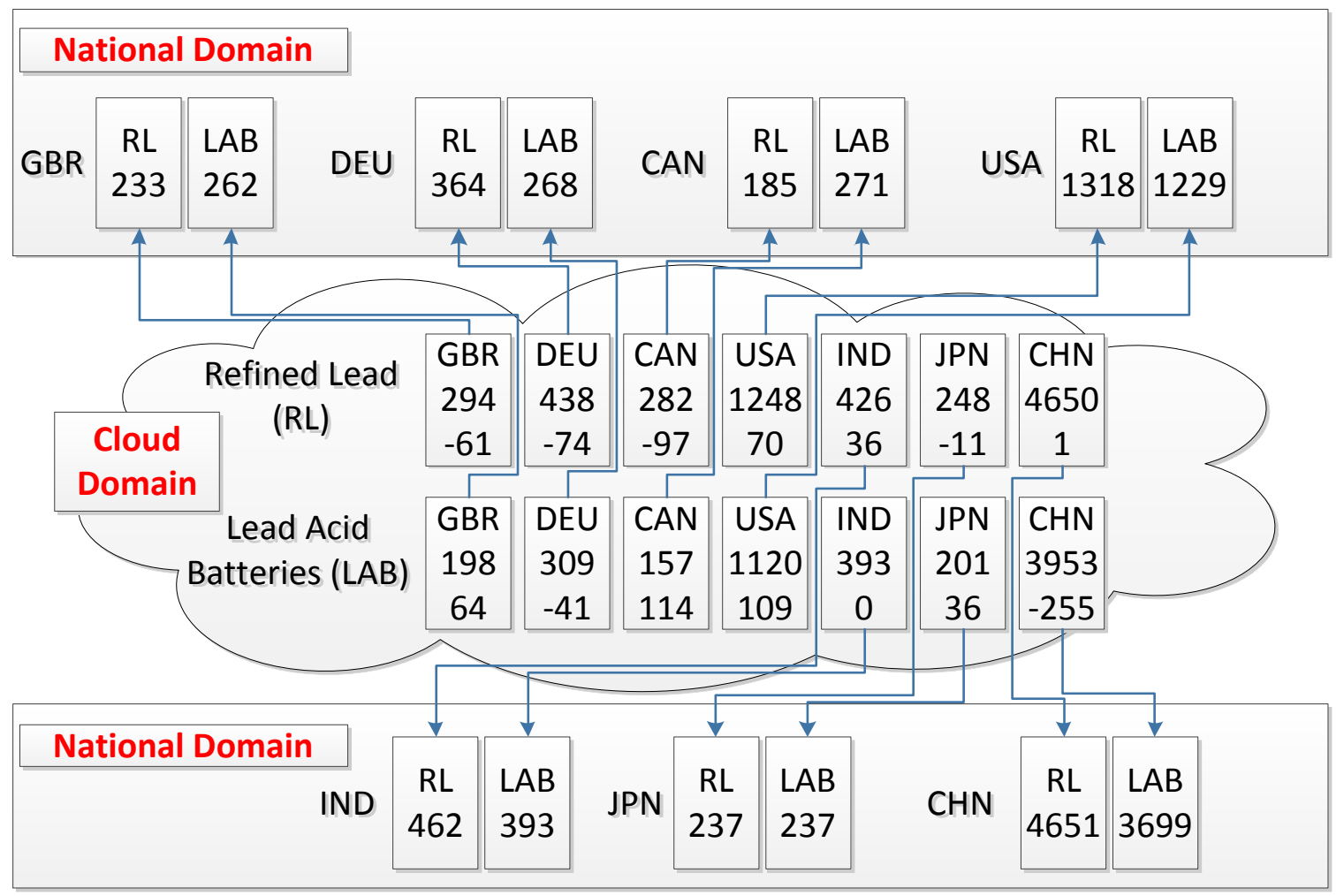

Figure 9 Lead Products Cloud

In conclusion it can be observed that the biggest producers and consumers of refined lead and LAB are China and the USA. However, the quantity that they represent in trade, (no more than $10 \%$ ) is quite small compared with their production, which means that there is a substantial amount of lead located in these two countries. Canada's production of lead is one quarter of that produced in the USA. However the majority of the production is directly exported to the USA (more than 90\%) with no significant material flow to anywhere else. 
Since all the information from the different countries is properly maintained in WR2Cloud, it is easy to locate the principal markets, producers and consumers. Additionally, it also provides an opportunity to modify the production strategy by considering the financial and environmental impacts. The lifecycle could be completed by using ULAB to produce new $L A B$ that is the currently the principle lead production method. These circumstances would help create regional management that could significantly reduce the environmental impact due to transportation and other informal practices.

\section{CONCLUSIONS AND PERSPECTIVES}

During the development of WR2Cloud, interviews were taken with different experts in the fields of component recovery and material recycling within the UK. From these interviews, some barriers for WEEE recovery were identified as follows:

\begin{tabular}{|c|c|c|}
\hline \multicolumn{2}{|r|}{ Barrier } & Solution \\
\hline Quantity & $\begin{array}{l}\text { The volume of WEEE is huge and the variety is } \\
\text { wide. }\end{array}$ & $\begin{array}{l}\text { Awareness about WEEE } \\
\text { production }\end{array}$ \\
\hline $\begin{array}{l}\text { Recovery } \\
\text { processes }\end{array}$ & $\begin{array}{l}\text { - It is difficult to establish universal operations due } \\
\text { to the diversity of WEEE in the market. } \\
\text { - The disassembly process is difficult due to the } \\
\text { lack of design considerations for material } \\
\text { recovery (recycling) or repairing (product } \\
\text { recovery) at EOL. Some joining methods may } \\
\text { simplify the manufacturing process and minimize } \\
\text { the product size and weight but hinder EOL } \\
\text { manipulation by for example preventing non- } \\
\text { destructive disassembly as in the case where } \\
\text { components are soldered or fused together or } \\
\text { where the Material is so fragile that dissemble } \\
\text { without breaking is impossible. } \\
\text { - Moreover, it is difficult to differentiate the } \\
\text { different materials of which the parts are } \\
\text { composed. }\end{array}$ & $\begin{array}{l}\text { Incentives to the OEM } \\
\text { for Design considering } \\
\text { Component Recovery or } \\
\text { Recycling aspects }\end{array}$ \\
\hline Lifetime & - The lifecycle of EEE is unpredictable due to & Incentives to the OEM \\
\hline
\end{tabular}




\begin{tabular}{|c|c|c|}
\hline & $\begin{array}{l}\text { different reasons for recovery. Some EEE are } \\
\text { destined for recycling and others for component } \\
\text { recovery but currently there is no system to } \\
\text { indicate which products or components should } \\
\text { be routed towards product recovery. } \\
\text { - The MOL is often shorter than the design lifetime } \\
\text { from OEMs. } \\
\text { - Nondurable materials are widely used in EEE, } \\
\text { especially for small electronic devices. These } \\
\text { materials may break or sustain other damage } \\
\text { during the recovery processes. However, it is } \\
\text { difficult to predict in advance the condition of } \\
\text { these materials at product EOL and thus set up } \\
\text { an appropriate recovery process. } \\
\text { - The evolution of EEE products is rapid due to the } \\
\text { swift changes in market trends. This volatility of } \\
\text { EEE products' technology makes it more difficult } \\
\text { to find customers for the recovered EEE. }\end{array}$ & $\begin{array}{l}\text { for Design considering } \\
\text { Component Recovery or } \\
\text { Recycling aspects }\end{array}$ \\
\hline $\begin{array}{l}\text { Rapid } \\
\text { Obsolescence }\end{array}$ & $\begin{array}{l}\text { - As the product and process technology for EEE is } \\
\text { rapid. Some products are withdrawn because of } \\
\text { the arrival of new models/versions as customers } \\
\text { may no longer want them because they do not } \\
\text { offer the latest functionality. The OEM may } \\
\text { prefer to stop their manufacture to make way for } \\
\text { the new models in order to compete on a } \\
\text { novelty basis with their competitors. }\end{array}$ & $\begin{array}{l}\text { Awareness about WEEE } \\
\text { production/recovery }\end{array}$ \\
\hline $\begin{array}{l}\text { Recovery } \\
\text { Cost }\end{array}$ & $\begin{array}{l}\text { - In some cases, the cost for recovering UEEE is } \\
\text { higher than producing or purchasing new } \\
\text { alternatives. } \\
\text { - From the customer's point of view, the price } \\
\text { advantage of a recovered product may be little } \\
\text { due to the labour, resource and facility utilization } \\
\text { required. In other cases, the remanufactured EEE } \\
\text { is even more expensive than new ones, despite } \\
\text { the environmental benefits. } \\
\text { - The general preference is directed to new } \\
\text { products from the economic point of view. } \\
\text { - In the case of considering producing competitive } \\
\text { UEEE, special facilities are required, which are } \\
\text { costly; skilled operators and technicians are also } \\
\text { needed. Currently skilled operators and } \\
\text { technicians are not yet available, especially in the } \\
\text { component recovery sector. } \\
\text { - Transportation of WEEE is another gap that is } \\
\text { identified. Since WEEE is considered as waste, it } \\
\text { contains a large volume of hazardous materials } \\
\text { after filtered and centralized. In many countries }\end{array}$ & $\begin{array}{l}\text { Incentives to the OEM } \\
\text { for Design considering } \\
\text { Component Recovery or } \\
\text { Recycling aspects } \\
\text { Incentives for the } \\
\text { consumers } \\
\text { To consider the EEE, } \\
\text { UEEE and WEEE } \\
\text { management in a } \\
\text { holistic way, as in a hub, } \\
\text { where OEM, recovers } \\
\text { and recyclers are } \\
\text { located closer. }\end{array}$ \\
\hline
\end{tabular}




\begin{tabular}{|c|c|c|}
\hline & $\begin{array}{l}\text { specific permission is needed, which increases } \\
\text { the cost and effort of transportation. }\end{array}$ & \\
\hline Awareness & $\begin{array}{l}\text { - Despite the impacts on environment, it is } \\
\text { challenging to convince manufacturers to } \\
\text { commercialize WEEE recovering and adopt } \\
\text { remanufacturing processes in the current supply } \\
\text { chain. } \\
\text { - The current market still lacks awareness of social } \\
\text { and environmental factors. } \\
\text { - It is also challenging to convince customers to } \\
\text { accept recovered EEE, or products containing } \\
\text { UEEE components. } \\
\text { - Since the warranty condition of these products } \\
\text { may be changed, it is difficult to persuade } \\
\text { consumers to choose recovered EEE or } \\
\text { components over premium models. It is } \\
\text { necessary to define the warranties respectively, } \\
\text { e.g. warranty for the whole product and } \\
\text { warranty for the recovered components. } \\
\text { - Although in some countries the disposal of WEEE } \\
\text { is separated from Municipal Solid Waste, the end } \\
\text { users still need more assistance for the WEEE } \\
\text { recovery, e.g. knowledge of classification and } \\
\text { disposal. Especially for recovery services, } \\
\text { consumers need to be supported by sufficient } \\
\text { information and knowledge regarding the } \\
\text { options for component recovery and recycling. }\end{array}$ & $\begin{array}{l}\text { Awareness to build } \\
\text { customer's purchase } \\
\text { motivation as sharing } \\
\text { knowledge related to } \\
\text { the hazardous materials } \\
\text { that could be reduced } \\
\text { thanks to the extended } \\
\text { lifecycle and the } \\
\text { recovery and recycling } \\
\text { service }\end{array}$ \\
\hline WEEE chain & $\begin{array}{l}\text { - The business model of WEEE recovering needs to } \\
\text { be reviewed and improved to encourage more } \\
\text { interactions with end users in order to take a } \\
\text { bigger market share. } \\
\text { - It is also difficult to involve end users in the } \\
\text { recovery supply chain. }\end{array}$ & $\begin{array}{l}\text { Generate a channel } \\
\text { where all the } \\
\text { stakeholders } \\
\text { (manufacturers, } \\
\text { collectors, dissemblers, } \\
\text { repair shops and } \\
\text { remanufacturers are } \\
\text { involved and able to } \\
\text { access to the } \\
\text { information and find } \\
\text { the better path. } \\
\text { (WR2Cloud) }\end{array}$ \\
\hline
\end{tabular}

In conclusion, the Cloud is a promising approach that provides better management and treatment of WEEE. It creates the opportunity of changing waste to valuable UEEE for the end-users, with numerous environmental benefits when properly 
applied. A WEEE recovery/recycling Cloud offers an organized platform where not only end-users are able to know how to deal with their used equipment, but also the whole of the supply and resupply chain including manufacturers, recyclers, remanufacturers, repairing shops and collectors are able to interact with the knowledge stored in the Cloud.

In this research, a Cloud-based recovery system is proposed, namely WR2Cloud. The current recovering/recycling resources and capabilities are integrated as Cloud services in the service-oriented infrastructure. With the help of the Cloud structure, the communication between users and service providers are supported by a distributed, flexible and intelligent network. Data sharing and exchange are further enhanced by the QR code methods. It is possible to track and manage the physical flow of WEEEs at both material level and component level. The Cloud environment provides a distributed platform to highlight, broadcast and share the advantage of WEEE recovery throughout the EEE supply and resupply chain. With reliable and dynamic information, the effectiveness of WEEE management will be greatly improved. The lead cycle was chosen as a case study to demonstrate how a WR2Cloud could be used in the global management of a substance as raw material and product, especially in order to locate the consumers and producers. Since WR2Cloud can act as the virtual depository of refined lead and $L A B$ due to the fact that they are interrelated for primary and secondary lead production it would enable the users to decide where would be the most convenient location for the suppliers or consumers. It is expected that, this type of global management could bring environmental and economic benefits. 
The interviews undertaken during the development of the WR2Cloud showed barriers related to quantity, recovery processes, and length of lifetime, obsolescence cost, customer awareness and understanding as well as the WEEE supply chain. These issues could be overcome by implementing legislation to ensure better collection channels. Standardized WEEE/UEEE definitions would also assist in creating a filter process before used electrical and electronic products are considered as waste. The commercialization of WEEE recovery/recycling options could be boosted through awareness, as this would help to gradually increase customers' willingness to purchase recovered WEEE. It also generates a channel in which all participants are involved in the EEE lifecycle. The consumers are able to access the information and find better path for their EEE when it reaches the EOL stage. Hazardous material management is another important consideration. End-users should be aware of what is contained in their WEEE and the options of WEEE recovery. The generation of hazardous material can be reduced, thanks to the extended lifecycle and the recovery service from WR2Cloud. Additionally, the recycling of WEEE has an important impact on the environment, because it reduces raw materials utilization from primary production, which leads to a decrease in the pollution generated from mining and industrial processes.

Future work would include further development of the supervisory mechanism of the recycling and component recovery Cloud to integrate and coordinate the services within one package. Customization and optimization solutions can be established with the help of a shared pool of knowledge and resources in the Cloud. User-friendly interfaces and mobile phone applications are also needed to evaluate the system and related methods. 
Mobile apps have particularly become powerful in recent years due to the increase in their mobility and flexibility. It will be helpful for the users to update WEEE data on mobile devices, and to easily link the service case with their location and contact details. As discussed above, the tracking and management of WEEE is difficult due to the lack of data feedback from end users. With the help of the Cloud and QR code mechanism, it is possible to establish close-loop control on the EEE/WEEE flow and achieve a high-level integration of the data and services.

\section{ACKNOWLEDGEMENTS}

This research is proposed as part of the Globally Recoverable and Eco-friendly Eequipment Network with distributed information service management (GREENet) project, Grant Agreement Number: PIRSES-GA-2010-269122. It was supported by a Marie Curie International Research Staff Exchange Scheme Fellowship within the 7th European Community Framework Programme.

\section{REFERENCES}

[1] US Environmental Protection Agency, 2012, "Statistics on the Management of Used and End-of-Life Electronics," http://www.epa.gov/wastes/conserve/materials/ecycling/manage.htm.

[2] Li, J., Lopez N, B. N., Liu, L., Zhao, N., Yu, K., and Zheng, L., 2013, "Regional or global WEEE recycling. Where to go?," Waste Management, 33(4), pp. 923-934.

[3] Li, J., Duan, H., and Shi, P., 2011, "Heavy metal contamination of surface soil in electronic waste dismantling area: site investigation and source-apportionment analysis," Waste Management \& Research, p. $0734242 X 10397580$.

[4] Sepúlveda, A., Schluep, M., Renaud, F. G., Streicher, M., Kuehr, R., Hagelüken, C., and Gerecke, A. C., 2010, "A review of the environmental fate and effects of hazardous substances released from electrical and electronic equipments during recycling: Examples from China and India," Environmental impact assessment review, 30(1), pp. 28-41. 
[5] Yang, X., Sun, L., Xiang, J., Hu, S., and Su, S., 2012, "Pyrolysis and dehalogenation of plastics from waste electrical and electronic equipment (WEEE): A review," Waste Management.

[6] Leung, A., Cai, Z. W., and Wong, M. H., 2006, "Environmental contamination from electronic waste recycling at Guiyu, southeast China," Journal of Material Cycles and Waste Management, 8(1), pp. 21-33.

[7] Lopez, B. N., Man, Y. B., Zhao, Y. G., Zheng, J. S., Leung, A. O. W., Yao, J., and Wong, M. H., 2011, "Major pollutants in soils of abandoned agricultural land contaminated by e-waste activities in Hong Kong," Archives of environmental contamination and toxicology, 61(1), pp. 101-114.

[8] Wu, J.-P., Luo, X.-J., Zhang, Y., Luo, Y., Chen, S.-J., Mai, B.-X., and Yang, Z.-Y., 2008, "Bioaccumulation of polybrominated diphenyl ethers (PBDEs) and polychlorinated biphenyls (PCBs) in wild aquatic species from an electronic waste (e-waste) recycling site in South China," Environment International, 34(8), pp. 1109-1113.

[9] Deng, W., Zheng, J., Bi, X., Fu, J., and Wong, M., 2007, "Distribution of PBDEs in air particles from an electronic waste recycling site compared with Guangzhou and Hong Kong, South China," Environment International, 33(8), pp. 1063-1069.

[10] Ni, K., Lu, Y., Wang, T., Kannan, K., Gosens, J., Xu, L., Li, Q., Wang, L., and Liu, S., 2013, "A review of human exposure to polybrominated diphenyl ethers (PBDEs) in China," International journal of hygiene and environmental health.

[11] Zhao, G., Wang, Z., Zhou, H., and Zhao, Q., 2009, "Burdens of PBBs, PBDEs, and PCBs in tissues of the cancer patients in the e-waste disassembly sites in Zhejiang, China," Science of the Total Environment, 407(17), pp. 4831-4837.

[12] Dimitrakakis, E., Janz, A., Bilitewski, B., and Gidarakos, E., 2009, "Small WEEE: Determining recyclables and hazardous substances in plastics," Journal of hazardous materials, 161(2), pp. 913-919.

[13] Ongondo, F., Williams, I., Dietrich, J., and Carroll, C., 2013, "ICT reuse in socio-economic enterprises," Waste Management, 33(12), pp. 2600-2606.

[14] Goodship, V., and Stevels, A., 2012, Waste Electrical and Electronic Equipment (WEEE) Handbook Woodhead Publishing.

[15] 2012, BS 8887-211. Design for Manufacture, Assembly, Disassembly and End-of-life processing (MADE) - Specification for reworking and remarketing of computing hardware.

[16] Ijomah, W., McMahon, C., Hammond, G., and Newman, S., 2007, "Development of robust design-forremanufacturing guidelines to further the aims of sustainable development," International Journal of Production Research, 45(18-19), pp. 4513-4536.

[17] Sobolewski, M., 2012, "Object-Oriented Service Clouds for Transdisciplinary Computing," Cloud Computing and Services Science, Springer, pp. 3-31.

[18] Xu, X., 2012, "From Cloud Computing to Cloud Manufacturing," Robotics and Computer-Integrated Manufacturing, 28(1), pp. 75-86. 
[19] Zhang, H. C., Li, J., Shrivastava, P., Whitley, A., and Merchant, M. E., 2004, "A web-based system for reverse manufacturing and product environmental impact assessment considering end-of-life dispositions," CIRP Annals-Manufacturing Technology, 53(1), pp. 5-8.

[20] Fidan, I., Roush, E. M., Tumkor, S., and Kraft, R. P., "Intelligent simulation environment for electronics remanufacturing systems," Proc. Electronics Manufacturing Technology Symposium, 2004. IEEE/CPMT/SEMI 29th International, IEEE, pp. 160-164.

[21] ISO, 1994, ISO 10303 -1: Industrial Automation Systems and Integration - Product Data Representation and Exchange - Part 1: Overview and Fundamental Principles.

[22] 2003, ISO 14649-1. Industrial Automation Systems and Integration - Physical Device Control - Data Model for Computerized Numerical Controllers - Part 1: Overview and Fundamental Principles.

[23] Wang, X. V., and Xu, X., 2013, "An Interoperable Solution for Cloud Manufacturing," Robotics and Computer-Integrated Manufacturing, 29(4), pp. 232-247.

[24] Swanson, L., 2001, "Linking maintenance strategies to performance," International Journal of Production Economics, 70(3), pp. 237-244.

[25] 2006, ISO/IEC 18004:Information technology -- Automatic identification and data capture techniques -- QR Code 2005 bar code symbology specification.

[26] CHR, 2014, "Global end-use breakdown of the lead consumption," Personal Communication.

[27] International Lead Association ILA, 2014, "Lead Recycling, Sustainability in action. Lead Action 21," http://www.ila-lead.org/UserFiles/File/ILA9927\%20FS_Recycling_V06.pdf.

[28] Dittrich, M., and Bringezu, S., 2010, "The physical dimension of international trade: Part 1: Direct global flows between 1962 and 2005," Ecological Economics, 69(9), pp. 1838-1847. 